\title{
Implant Replacement or Removal: What Happens after Capsular Contracture? A German Study Examining Breast Implant Revision Surgery and Patient Choices in 946 Cases
}

\author{
Shafreena Kühn ${ }^{a} \quad$ Mara Anna Georgijewitsch ${ }^{b} \quad$ Andrej Wehle ${ }^{a} \quad$ Moritz Billner $^{c}$ \\ Lara Küenzlen $^{a} \quad$ Jens Rothenberger ${ }^{a} \quad$ Ulrich Michael Rieger ${ }^{a}$ \\ aDepartment of Plastic and Aesthetic, Reconstructive and Hand Surgery, AGAPLESION Markus Hospital, Academic \\ Teaching Hospital Goethe University, Frankfurt am Main, Germany; ${ }^{b}$ Department of Surgery, Schlosspark Hospital, \\ Berlin, Germany; ' Department of Plastic, Reconstructive and Hand Surgery, Nurnberg South Hospital, Nuremberg, \\ Germany
}

\section{Keywords}

Breast surgery · Breast augmentation · Implants .

Mastopexy · Capsular contracture

\begin{abstract}
Introduction: Capsular contracture most often leads to implant revision surgery for aesthetic or reconstructive purposes. However, little is known about which operation is chosen when revision surgery has to be performed. We performed analysis of revision indications and performed revision surgery considering implant removal or replacement and additional surgical procedures. To our knowledge, this study presents the largest German single-center analysis regarding implant revision surgery after the onset of complications. Methods: Retrospective 10-year data analysis of a singlecenter population undergoing breast implant revision surgery. Results: Capsular contracture was the most frequent finding before reoperation, both removal and replacement $(p<0.05)$. It was linked to longer duration of in situ implant placement $(p<0.05)$ and more frequently in reconstructive patients $(p<0.05)$. Implant replacement was performed more often before definite implant removal for reconstructive patients $(p<0.05)$. Mean duration of in situ implant placement before definite removal was lower for reconstructive patients $(p=0.005)$. Overall reconstructive patients were older than aesthetic patients $(p<0.05)$. After implant remov-
\end{abstract}

al, $61.7 \%$ of aesthetic patients chose to undergo mastopexy, $54.7 \%$ of reconstructive patients opted for autologous breast reconstruction, and $25.4 \%$ did not choose an additional surgical procedure after implant removal. Conclusion: Significant differences are observed for reconstructive and aesthetic patients regarding indication leading to revision surgery, time of revision surgery, and the type of performed revision surgery itself. After implant removal, more than $60 \%$ of aesthetic patients undergo mastopexy, more than half of reconstructive patients choose autologous breast reconstruction, and over a quarter of patients choose no additional surgical procedures.

○ 2020 S. Karger AG, Basel

\section{Introduction}

The aesthetics of the breast has been a topic of great interest and concern over the last decades [1]. This is mirrored by the frequency of performed aesthetic breast surgery worldwide, as numbers provided by the ISAPS show [2]. Since the first introduction of breast implants in the 1960s [3], requests for implant-based breast augmentation have soared. In 2018, over 3.5 million breast surgeries were registered worldwide, more than half of which were breast augmentations [2]. Since their introduction, multiple publications have shown the various short- and 
long-term implications associated with breast implants for aesthetic and reconstructive indications [4-11]. One of the earlier major studies published in 1997 in the New England Journal of Medicine, over 30 years after the introduction of breast implantation, showed that capsular contracture was the most frequent indication for revision surgery after placement of breast implants, followed by rupture of the implant and other surgical complications, such as hematoma and wound infection [5]. A very recent study from 2019 published in the Annals of Surgery, over half a century after implant introduction, presented longterm outcomes in almost 100,000 patients following breast implantation in the United States, confirming the findings from the study in 1997 and showing capsular contracture and implant rupture to still remain one of the main indications for reoperation [6]. Depending on whether implants were placed for aesthetic or reconstructive purposes and whether primary or revision surgery took place, Coroneos et al. [6] presented reoperation rates ranging from 4.5 to $26.6 \%$ and implant removal rates between 2.4 and $17.4 \%$. As a consequence of arising complications, patients seek medical advice leading to revision surgery, which often proves to be the only effective treatment. Besides the replacement of a complication-inducing breast implant with a new implant, patients may also opt for a definite removal of the breast implant. Such indications and further consequences of definite explantation of breast implants have been explored by several publications [7, 12-18]. Medical indications but also patient choices may vary concerning the treatment of implant complications. It is the objective of this study to display and compare the indications for and moreover the frequency of performed implant removal, implant replacement, and other additional surgical procedures for aesthetic and reconstructive purposes, in order to increase understanding of patients' choices and needs, thus optimizing patient information and treatment possibilities.

\section{Materials and Methods}

This retrospective study sought to analyze a patient population from our Department for Plastic and Reconstructive Surgery at AGAPLESION Markus Hospital Frankfurt am Main, Germany, which underwent revision surgery attending breast implant-based complication, requiring implant removal or replacement and other additional surgical procedures. This patient population consisted of females only with no age restriction. Both reconstructive and aesthetic purposes were included for analysis in this study. Reconstructive patients included patients who underwent breast surgery for oncological reasons, as well as benign breast tumors, mastopathy, or congenital malformations.

Data collection was performed through revision of patient records manually and digitally. Indications for revision surgery, as well as the actual revision surgery performed, that is, implant removal, implant replacement, or other surgical procedures, were measures for this study. Furthermore, the number of previously performed revisions for breast implant complication and the timeframe of implant placement were examined. Data were collected for each patient and breast, and all data are presented in this study. Collected data were analyzed and sorted using IBM SPSS Statistics, Version 23, IBM SPSS, Chicago, IL, USA, and visualized using Microsoft Excel Version 16.16.7 and GraphPad Prism 8.4.1.

\section{Results}

During our period of examination between 2006 and 2016, a total of 591 female patients underwent revision surgery at the Department of Plastic and Aesthetic Surgery at AGAPLESION Markus Hospital Frankfurt am Main, Germany. The mean patient age was 54.6 years (range 19-88 years). Out of these patients, 449 (76\%) underwent implant replacement and 142 (24\%) received a definitive removal of the implant. Out of the total $591 \mathrm{pa}-$ tients, 378 (64\%) had surgery for reconstructive purposes and 213 (36\%) underwent surgery for aesthetic reasons. Regarding separate breasts, revision surgery was performed on a total of 946 breasts during our 10-year study analysis. Out of these, $40.7 \%(n=385)$ were for aesthetic and $59.3 \%(n=561)$ for reconstructive purposes. Overall, $78.8 \%(n=745)$ implant replacements and $21.2 \%(n=$ 201) implant removals took place (Fig. 1).

\section{Implant Replacement Group}

This group of patients $(n=414)$ included $37.0 \%(n=$ 166) aesthetic and $63.0 \%(n=283)$ reconstructive patients. Within this group, a total of 745 breast implants (aesthetic 40.4\%, $n=301$; reconstructive 59.6\%, $n=444$ ) were replaced during our period of analysis (Fig. 1). Patients with aesthetic indications were of younger age (average 49.9 years) compared to the reconstructive group (57.3 years), showing statistical significance $(p=0.000)$. For patients receiving one or more implant replacements, aesthetic indications showed a mean time of in situ implant duration of 12.9 years, as compared to the reconstructive group, showing a mean time span of 12.0 years before (first or repeated) implant replacement.

With respect to indication for revision surgery for each breast, the most common indication was capsular contracture for both the aesthetic and reconstructive group (overall breasts $80.3 \%, n=598$; aesthetic $72.4 \%, n=218$; reconstructive $85.6 \%, n=380)$. Capsular contracture was linked to longer duration of in situ placement of implant $(p=0.000)$, as well as reconstructive breast augmentation $(p=0.003)$. Implant replacement rather than removal was performed significantly more often for reconstructive patients than aesthetic patients when faced with capsular contracture $(p=0.0074)$ and implant rupture $(p=0.0001)$, whereas implant replacement was performed more often in aesthetic patients with tissue damage and implant exposure com- 


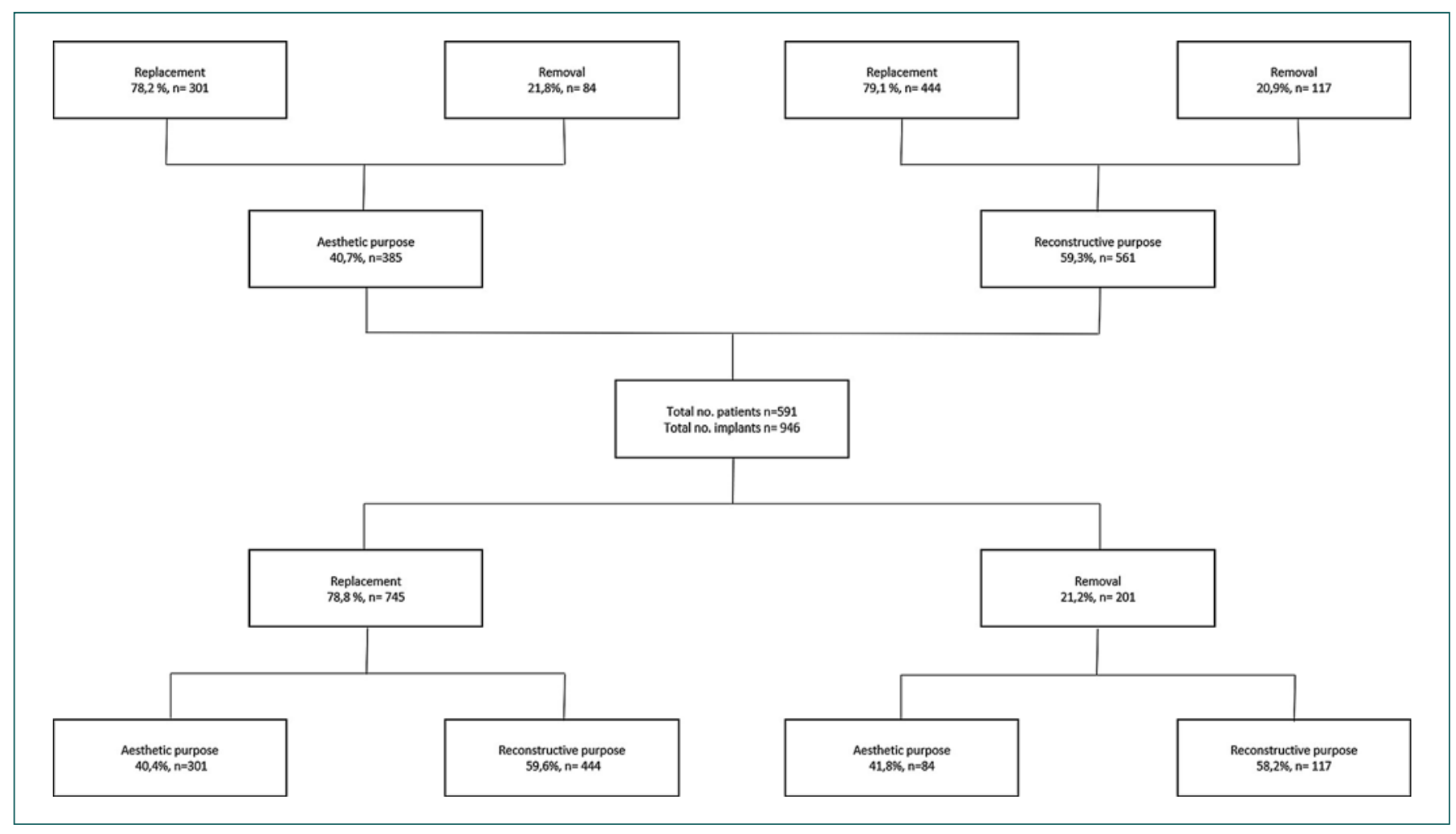

Fig. 1. Overview of all patients and breast implants placed according to initial purpose of implant placement and revision surgery. Numbers and figures refer to number of breasts.

Table 1. Detailed summary of findings at time of revision surgery (replacement or removal) according to initial purpose of implant placement

\begin{tabular}{|c|c|c|c|c|}
\hline & \multicolumn{2}{|c|}{ Replacement } & \multicolumn{2}{|l|}{ Removal } \\
\hline & $\begin{array}{l}\text { aesthetic } \\
\text { purpose }\end{array}$ & $\begin{array}{l}\text { reconstructive } \\
\text { purpose }\end{array}$ & $\begin{array}{l}\text { aesthetic } \\
\text { purpose }\end{array}$ & $\begin{array}{l}\text { reconstructive } \\
\text { purpose }\end{array}$ \\
\hline Overall & $40.4(301)$ & $59.6(444)$ & $41.8(84)$ & $58.2(117)$ \\
\hline Capsular contracture & $72.4(218)$ & $85.6(380)$ & $78.6(66)$ & $59.0(69)$ \\
\hline Implant rupture & $49.5(149)$ & $49.8(221)$ & $76.2(64)$ & $34.2(40)$ \\
\hline Patient wish & $15.3(46)$ & $15.3(68)$ & $29.8(25)$ & $22.2(26)$ \\
\hline Implant dislocation & $7.3(22)$ & $14.0(62)$ & $7.1(6)$ & $6.8(8)$ \\
\hline Infection & $12.6(38)$ & $9.5(42)$ & $11.9(10)$ & $18.8(22)$ \\
\hline Following national advice & $19.6(59)$ & $3.2(14)$ & $6.0(5)$ & $0.0(0)$ \\
\hline Suspicious lesion & $7.6(23)$ & $5.0(22)$ & $2.4(2)$ & $6.0(7)$ \\
\hline Tissue damage & $3.3(10)$ & $2.9(13)$ & $1.2(1)$ & $21.4(25)$ \\
\hline
\end{tabular}

Summary of proportion of breasts in percentage (number of breasts).

pared to reconstructive patients $(p=0.0009)$. In terms of indication frequency, capsular contracture was followed by damage of breast implant (overall 49.7\%, $n=370$ ). Regarding preoperative suspected damage of implant, this was confirmed intraoperatively in $56.5 \%(n=209)$ of cases; for $43.5 \%(n=161)$, no implant damage was found.

Overall, dislocated breast implants were found in $11.3 \%(n=84)$ of breasts (aesthetic 7.3\%, $n=22$; reconstructive $14.0 \%, n=62$ ).
Subclinical infection was an indication for implant replacement in $10.7 \%$ (overall $n=80$; aesthetic $12.6 \%, n=$ 38; reconstructive 9.5\%, $n=42$ ). Exposure of implant due to overlying tissue damage occurred in $3.1 \%(n=23)$ of breasts receiving implant replacement (aesthetic 3.3\%, $n=10$; reconstructive $2.9 \%, n=13$ ). Within the aesthetic group, $19.6 \%(n=59)$ breast implants were replaced following national advice through the German Federal Institute for Drug and Medical Devices (BfArM) for remov- 
Table 2. Outline of statistically significant findings for this study

\begin{tabular}{lc}
\hline & $p$ value \\
\hline Capsular contracture is linked to longer duration of in situ placement of implant & 0.000 \\
\hline Capsular contracture is more frequent in reconstructive compared to aesthetic patients & 0.003 \\
\hline Capsular contracture was the most frequently presented finding before implant removal for overall patients & 0.008 \\
\hline Capsular contracture more often leads to replacement rather than removal for overall patients & 0.001 \\
$\begin{array}{l}\text { Capsular contracture and implant rupture are more often linked to implant replacement (with higher replacement } \\
\text { frequencies) rather than definite removal in reconstructive patients compared to aesthetic patients }\end{array}$ & 0.0074 and \\
\hline $\begin{array}{l}\text { Tissue damage is more often linked to implant replacement rather than definite removal in aesthetic patients } \\
\text { compared to reconstructive patients }\end{array}$ & 0.0001 \\
\hline $\begin{array}{l}\text { Tissue damage was more frequently linked to definite removal compared to replacement for overall patients } \\
\text { Infection was more frequently linked to definite removal compared to replacement for overall patients }\end{array}$ & 0.000 \\
\hline $\begin{array}{l}\text { Longer mean duration of in situ implant placement before definite removal in aesthetic compared to reconstructive } \\
\text { patients }\end{array}$ & 0.005 \\
\hline
\end{tabular}

Higher proportion of multiple implant replacements prior to definite removal in reconstructive patients compared to 0.015 aesthetic patients

Higher mean age at time of implant removal and replacement in reconstructive compared to aesthetic patients

0.001

al of Poly Implant Prothése (PIP\&Rofil) following the European scandal [4]. Table 1 outlines findings at time of revision surgery in detail for this group of patients.

Within the implant replacement group, $13.7 \%(n=67)$ of patients requested further surgical procedures regarding breast appearance; this included mastopexy for $10.2 \%$ $(n=50)$ patients of both the aesthetic and reconstructive groups. Furthermore, for reconstructive patients, $2.9 \%$ procedures on the contralateral breast, as well as $0.6 \%$ for additional placement of autologous tissue, lipofilling, and modified mastectomy were performed.

\section{Implant Removal Group}

The cohort undergoing implant removal $(n=142)$ was made up of $33.1 \%(n=47)$ aesthetic and $66.9 \%(n=95)$ reconstructive patients. Within this group, a total of 201 breast implants (aesthetic $41.8 \%, n=84$; reconstructive $58.2 \%, n=117$ ) were removed during our period of analysis. There was a significant difference in age at the time of implant removal for aesthetic (mean 50.3 years) and reconstructive patients (mean 56.2 years; $p=0.001$ ).

Mean duration of in situ implant placement before definite removal differed significantly for reconstructive (mean 9.0 years) and aesthetic (mean 15.8 years) patients $(p=0.005)$.

Definite removal of breast implant was the reason for the first revision surgery after initial placement of breast implant for $76.2 \%(n=64)$ of aesthetic and $52.1 \%(n=61)$ of reconstructive placed breast implants. $47.9 \%(n=56)$ of reconstructively placed implants had been replaced more than once previously to implant removal, compared to $23.8 \%(n=20)$ of aesthetically placed breast implants $(p=0.015)$. Capsular contracture $(67.2 \%, n=135)$ was the most frequent reason for implant removal in both the aesthetic $(78.6 \%, n=66)$ and reconstructive $(59.0 \%, n=69)$ group per breast $(p=0.008)$.

Capsular contracture was followed by suspected implant damage (aesthetic $76.2 \%, n=64$; reconstructive $59.0 \%, n=69$ ) and patients' request (aesthetic 29.8\%, $n=$ 25 ; reconstructive $22.2 \%, n=26$ ) for breast implant removal. Table 1 outlines findings at the time of revision surgery in detail for this group of patients.

Within the group undergoing definite implant removal, 25.4\% $(n=36)$ of patients did not receive additional surgical procedures (aesthetic $31.9 \%, n=15$; reconstructive $22.1 \%, n=21)$, whereas $33.1 \%(n=47)$ opted for an additional mastopexy after implant removal (aesthetic $61.7 \%, n=29$; reconstructive $18.9 \%, n=18) .54 .7 \%(n=$ 52) of reconstructive patients had autologous tissue transfer for breast reconstruction after removal of breast implant. 2.8\% $(n=4)$ opted for lipofilling and $2.1 \%(n=3)$ solely reconstructive patients opted for an ablation of the breast.

Analysis of both replacement and removal groups in comparison, shows significant results for capsular contraction with regard to implant replacement $(80.3 \%, n=$ $598)$ or implant removal $(67.2 \%, n=135)$, showing more replacement than removals, when capsular contraction is the reason for revision surgery $(p=0.001)$. Patients opting for implant replacement showed more severe cases of 
Fig. 2. a 35-year-old patient with bilateral capsular contracture 12 years after aesthetic breast augmentation. b Six months after capsular excision and implant replacement.

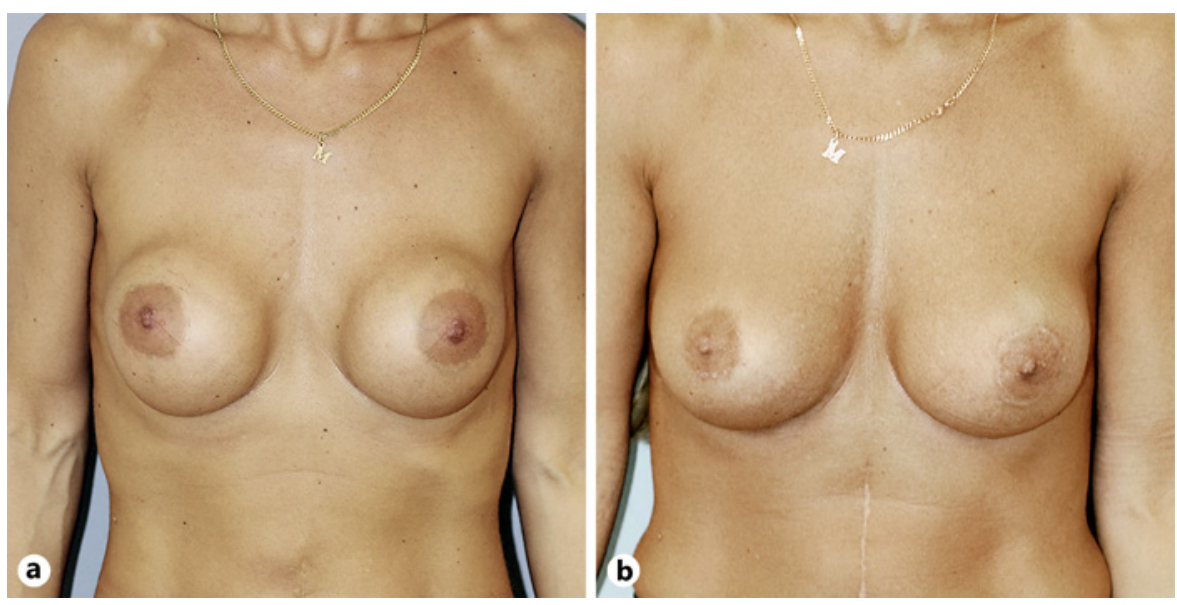

capsular contracture (Baker III or IV) in comparison to patients requesting definite removal, whereas twice as many requesting definite removal showed no or mild signs of capsular contracture (removal 25.0\%; replacement $12.5 \%$ ). Infection was diagnosed 1.5 times more often in the removal cohort than for replacement (removal $15.9 \%$; replacement $10.7 \%$; $p=0.045$ ). Similarly, skin or overlying tissue damage and subsequent implant exposure was 4 times higher in the removal cohort compared to the replacement group (removal 12.9\%; replacement $3.3 \% ; p=0.000$ ).

However, no significant differences in mean patient age or regarding decision making on implant removal or replacement for aesthetic or reconstructive patients were found. 2.

All statistically significant results are outlined in Table

\section{Discussion/Conclusion}

Breast implantations have been a steady companion of plastic and oncological breast surgeons, from their beginnings in the early 1960s [3]. Lately, breast implants have again attracted the attention of public interest due to their connection to breast implant-associated anaplastic large cell lymphoma [19-22]. Besides this very serious and malignant, yet only quite recently discovered complication, drastically more frequent complications, such as capsular contracture, implant rupture and dislocation, or infection, have been described and thoroughly analyzed over the past centuries $[11,23]$. It is, thus, well known that capsular contracture occurs with notoriously high frequency in breast implant holders, with publications describing occurrence rates of up to $50 \%$ [24]. Unfortunately, this has not changed over the course of time, as very recent large-scale studies have shown [6]. This fact might be due to the still widely unknown detailed causes of cap- sular contracture. Although several coinciding and influencing factors have been described [9,24-26], exact processes regarding development of capsular contracture and, hence, exact measures for prevention of occurrence have yet to be discovered and understood with certainty $[24,27]$.

With occurrence of implant complications of any nature, patients generally seek medical and surgical advice, which depending on the individual circumstances often leads to revision surgery, as is the case with the most common complication of capsular contracture in its later and more severe stages. Besides this leading complication, other indications might also lead to revision surgery, such as damage or dislocation of implant, but also infections and even implant exposure. Also, patients might desire implant replacement or even a definite removal of implants, independent of objectifiable complications. Due to the rising number of patients with breast implants, the number of revision surgeries may be expected to remain at least constant. Data concerning the actual revision surgery performed are comparably sparse [7, 12-18, 28], while complications leading to revision surgery are intensely analyzed and widely published. As Boer et al. [7] stated "very few studies deal with the type of reconstruction of explanted breasts... more research should be done regarding this issue." Besides the type of reconstruction performed after implant removal, our study examined the rate at which explantations were performed in the first place, as well as looking into the additional surgical procedures performed in order to reconstruct the breast. Also, the rates of implant replacements were examined in addition to explantation.

As patients seeking revision surgery for reconstructive purposes mostly concern oncological patients, a significantly higher mean age for revision surgery for this group of patients is comprehensible, as oncological matters arise more often at a later age. The rate for capsular contracture as an indication for revision surgery of any kind was sig- 
Fig. 3. a 60 -year-old patient with bilateral waterfall deformity 14 years after aesthetic breast augmentation. b Six months after implant removal and mastopexy.
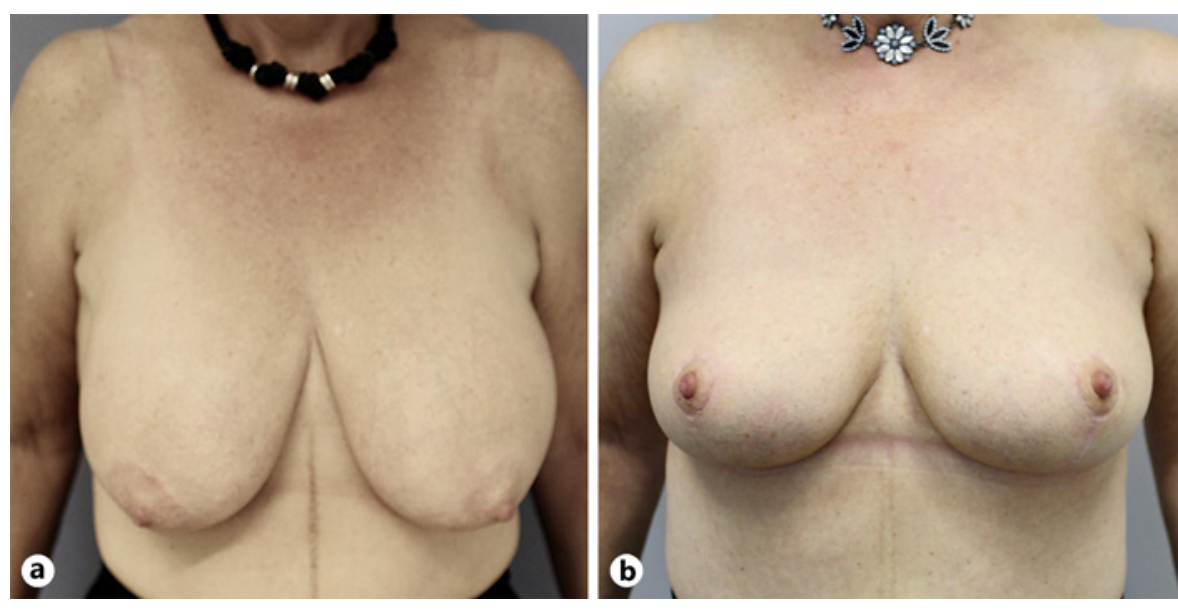

Fig. 4. a 40-year-old patient with capsular contracture after implant placement following incomplete mastectomy for breast cancer (left side). b Six months after implant removal and autologous tissue transfer (DIEP-Flap).
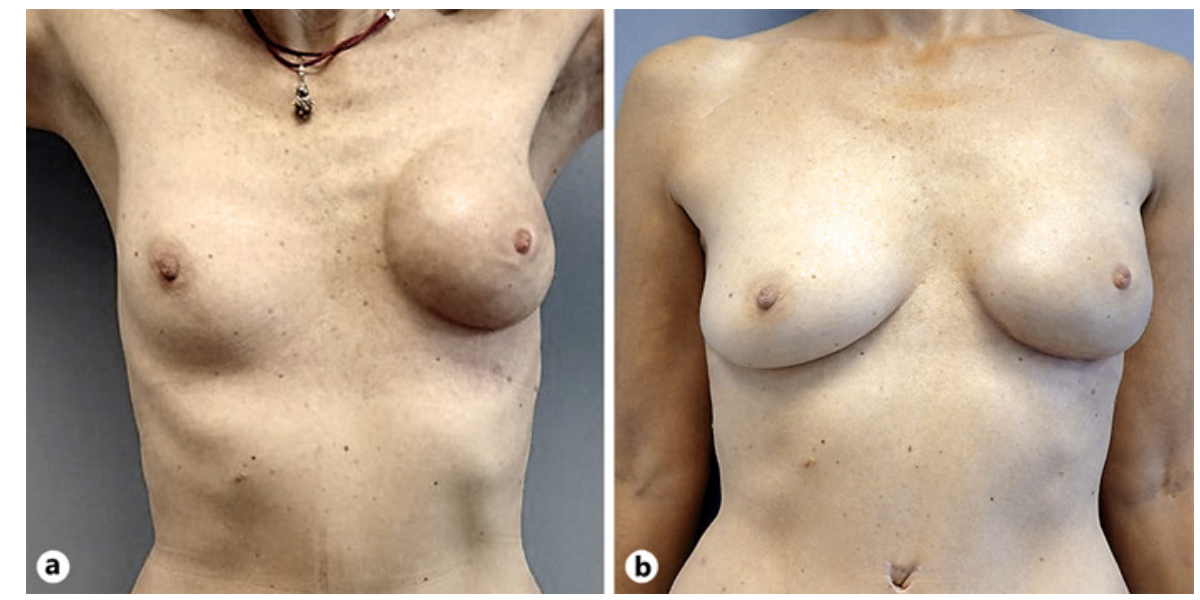

nificantly high, also matching results of various published data. However, for our patient population, significantly higher rates of implant replacement were observed (Fig. 2), as compared to explantation of implant for capsular contracture. This was in stark contrast to exposure of implant, which significantly more often led to implant removal, rather than replacement. This was equally the case for infection as an indication for revision surgery. This might also be underlined by the finding of twice as many severe cases of capsular contracture for the replacement group compared to definite removal, as this may mirror that although capsular contracture is observed most frequently for implant replacement, it might not be the final influencing factor leading to implant explantation. An interpretation of these results may be, that although capsular contracture is a nuisance, especially in its frequency, it still presents a rather manageable complication, which is adequately treated not requiring a definite implant removal. However, for infection or deficiency of overlying tissue, this may not be the case. Infection often does not allow an immediate implant replacement, as the infectious site may need to be cleared and reconstituted first. Similarly, deficiency of overlying tissue was found at a significantly higher rate for the removal group. Overlying tissue deficiency leads to exposure of implant and may also involve infection of the implant site due to the missing skin barrier, equally not allowing immediate implant replacement. Besides these common indications, patients might present other relevant objective or subjective reasons for explantation [7]. Capsular contracture was significantly associated with longer duration of implant placements, as well as higher rates for reconstructive patients, also reflecting published data in the current literature [9]. It was further observed that dislocation of the implant was followed by implant replacement twice more often than implant removal.

For patients requiring definite implant removal, in over $60 \%$ of aesthetic cases, an additional mastopexy was opted for in order to reconstruct breast shape (Fig. 3); over half of the revision procedures for the reconstructive group were breast reconstruction using autologous tissue transfer (Fig. 4). About one-quarter of definite implant removal procedures did not include additional surgical methods for further reconstruction. This mirrors the de- 


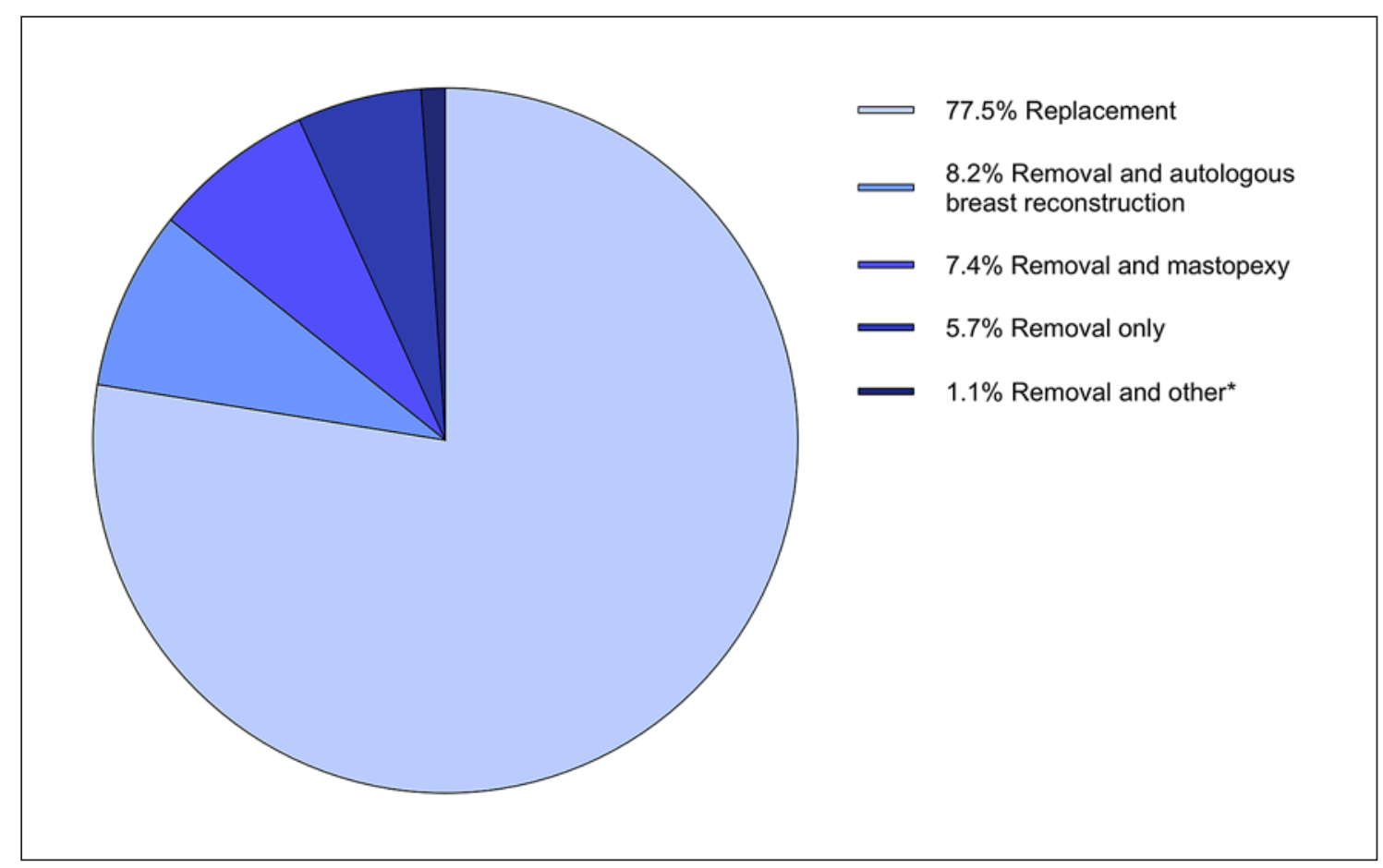

Fig. 5. Overview of revision surgery performed for all patients $(n=591) .{ }^{*}$ Includes implant removal and lipofilling or ablation of the breast.

sire and need of about three-quarters of patients undergoing implant removal for breast reconstruction in one way or another. In broader perspective, taking all documented procedures into account, about $6 \%$ of all procedures did not involve further reconstructive measures. About $94 \%$ of all procedures included either implant replacement or removal in combination with further reconstructive measures (Fig. 5). This depicts the importance of a reconstructed breast after implant complication or implant revision surgery, as also reflected by numerous studies examining positive body image and quality of life after breast reconstruction [29-33].

Overall, this study depicts a large-scale single center analysis regarding indications leading to revision surgery, as well as the performed revision surgery itself. Groups were classified according to performed revision surgery, that is, implant replacement or removal, as well as according to initial indication for breast implantation, that is, aesthetic or reconstructive purposes. Results show capsular contracture to be a significantly high complication factor leading to revision surgery. However, our results suggest that this complication significantly more often leads to implant replacement, rather than definite removal, especially for reconstructively augmented patients. In contrast, infection and overlying skin damage leading to implant exposure significantly more often resulted in definite implant removal. Overall, more than $94 \%$ of revision surgeries include some sort of breast re- construction measures, whether it is implant replacement or mastopexy or autologous tissue transfer after implant removal. Only about $6 \%$ of revision procedures include sole implant removal with no further surgical reconstruction measures. Thus, the reconstruction of breast shape or volume after revision surgery is essential and requested by the vast majority of aesthetic and reconstructive patients, leaving only a small minority of patients opting for a definite removal of the implant with no further reconstruction.

\section{Statement of Ethics}

All patients have given their written informed consent, and the study protocol was approved by the institute's committee on human research (Ethikkommission der Landesärztekammer Hessen; FF36/2018).

\section{Conflict of Interest Statement}

The authors have no conflicts of interest to declare.

\section{Funding Sources}

The authors have no funding sources to declare. 


\section{Author Contributions}

S.K.: conception of the study, analysis and interpretation of data, drafting and revision of manuscript, final approval of version, agreeing to be accountable for all aspects of the work. M.A.G.: acquisition, analysis and interpretation of data, revision of manuscript, final approval of version, agreeing to be accountable for all aspects of the work. A.W., M.B., L.K., and J.R.: analysis and interpretation of data, revision of manuscript, final approval of version, agreeing to be accountable for all aspects of the work. U.M.R.: conception of the study, analysis and interpretation of data, revision of manuscript, final approval of version, agreeing to be accountable for all aspects.

\section{References}

1 Kühn S, Rieger UM. Ästhetische Operationen - nimmt der Trend zu? Gynakol Praxis. 2018; 44(2):309-16.

2 International Society of Aesthetic Plastic Surgery [Internet]. ISAPS international survey on aesthetic/cosmetic procedures performed in 2018. Available from: https://www.isaps. org/wp-content/uploads/2019/12/ISAPS Global-Survey-Results-2018-new.pdf.

3 Champaneria MC, Wong WW, Hill ME, Gupta SC. The evolution of breast reconstruction: a historical perspective. World J Surg. 2012 Apr;36(4):730-42.

4 Billner M, Wirthmann A, Reif S, Rieger UM. Poly Implant Prothèse and Rofil Substandard Breast Implant Explantations from a Large German Single Centre from 2011 to 2014: A Comparative Study. Aesthetic Plast Surg. 2016 Aug;40(4):507-13.

5 Gabriel SE, Woods JE, O'Fallon WM, Beard CM, Kurland LT, Melton LJ 3rd. Complications leading to surgery after breast implantation. N Engl J Med. 1997 Mar;336(10):67782.

6 Coroneos CJ, Selber JC, Offodile AC 2nd, Butler CE, Clemens MW. US FDA Breast Implant Postapproval Studies: Long-term Outcomes in 99,993 Patients. Ann Surg. 2019 Jan; 269(1):30-6.

7 de Boer M, Colaris M, van der Hulst RR, Cohen Tervaert JW. Is explantation of silicone breast implants useful in patients with complaints? Immunol Res. 2017 Feb;65(1):25-36.

8 Van Slyke AC, Carr M, Carr NJ. Not All Breast Implants Are Equal: A 13-Year Review of Implant Longevity and Reasons for Explantation. Plast Reconstr Surg. 2018 Sep;142(3): 281e-9e.

9 Bachour Y, Bargon CA, de Blok CJ, Ket JC, Ritt MJ, Niessen FB. Risk factors for developing capsular contracture in women after breast implant surgery: A systematic review of the literature. J Plast Reconstr Aesthet Surg. 2018 Sep;71(9):e29-48.

10 Chopra K, Gowda AU, Kwon E, Eagan M, Grant Stevens W. Techniques to Repair Implant Malposition after Breast Augmentation: A Review. Aesthet Surg J. 2016 Jun;36(6): 660-71.

11 Maxwell GP, Van Natta BW, Bengtson BP, Murphy DK. Ten-year results from the $\mathrm{Na}$ trelle 410 anatomical form-stable silicone breast implant core study. Aesthet Surg J. 2015 Feb;35(2):145-55.
12 Borenstein A, Friedman O. Combined Breast Implant Explantation and Multilevel Mastopexy Technique. Plast Reconstr Surg Glob Open. 2019 Sep;7(9):e2429.

13 Netscher DT, Sharma S, Thornby J, Peltier M, Lyos A, Fater M, et al. Aesthetic outcome of breast implant removal in 85 consecutive patients. Plast Reconstr Surg. 1997 Jul;100(1): 206-19.

14 Paydar KZ, Kohan E, Hansen SL, Roostaeian J, Gradinger GP. Long-term effects of breast aging in patients undergoing explantation: analysis of breast aesthetics from before augmentation to after explantation. Ann Plast Surg. 2013 Apr;70(4):427-31.

15 Graf RM, Closs Ono MC, Pace D, Balbinot P, Pazio AL, de Paula DR. Breast Auto-augmentation (Mastopexy and Lipofilling): An Option for Quitting Breast Implants. Aesthetic Plast Surg. 2019 Oct;43(5):1133-41.

16 Gurunluoglu R, Kubek E, Arton J. Dual pedicle mastopexy technique for reorientation of volume and shape after subglandular and submuscular breast implant removal. Eplasty. 2013 Sep; 13:e48.

17 Hönig JF, Frey HP, Hasse FM, Hasselberg J. Inferior pedicle autoaugmentation mastopexy after breast implant removal. Aesthetic Plast Surg. 2010 Aug;34(4):447-54.

18 Gurunluoglu R, Sacak B, Arton J. Outcomes analysis of patients undergoing autoaugmentation after breast implant removal. Plast Reconstr Surg. 2013 Aug;132(2):304-15

19 Collett DJ, Rakhorst H, Lennox P, Magnusson M, Cooter R, Deva AK. Current Risk Estimate of Breast Implant-Associated Anaplastic Large Cell Lymphoma in Textured Breast Implants. Plast Reconstr Surg. 2019;143(3S): 30S-40S.

20 Ramos-Gallardo G, Cuenca-Pardo J, Rodríguez-Olivares E, Iribarren-Moreno R, Contreras-Bulnes L, Vallarta-Rodríguez A, et al. Breast Implant and Anaplastic Large Cell Lymphoma Meta-Analysis. J Invest Surg. 2017 Feb;30(1):56-65.

21 Leberfinger AN, Behar BJ, Williams NC, Rakszawski KL, Potochny JD, Mackay DR, et al. Breast Implant-Associated Anaplastic Large Cell Lymphoma: A Systematic Review. JAMA Surg. 2017 Dec;152(12):1161-8.

22 Rastogi P, Deva AK, Prince HM. Breast Implant-Associated Anaplastic Large Cell Lymphoma. Curr Hematol Malig Rep. 2018 Dec; 13(6):516-24.
23 Spear SL, Murphy DK; Allergan Silicone Breast Implant U.S. Core Clinical Study Group. Natrelle round silicone breast implants: core Study results at 10 years. Plast Reconstr Surg. 2014 Jun;133(6):1354-61.

24 Galdiero M, Larocca F, Iovene MR, Martora F, Pieretti G, D'Oriano V, et al. Microbial Evaluation in Capsular Contracture of Breast Implants. Plast Reconstr Surg. 2018 Jan; 141(1):23-30

25 Li S, Chen L, Liu W, Mu D, Luan J. Capsular Contracture Rate After Breast Augmentation with Periareolar Versus Other Two (Inframammary and Transaxillary) Incisions: A MetaAnalysis. Aesthetic Plast Surg. 2018 Feb; 42(1):32-7.

26 Calobrace MB, Stevens WG, Capizzi PJ, Cohen R, Godinez T, Beckstrand M. Risk Factor Analysis for Capsular Contracture: A 10-Year Sientra Study Using Round, Smooth, and Textured Implants for Breast Augmentation. Plast Reconstr Surg. 2018 Apr;141(4S):20S$28 \mathrm{~S}$.

27 Vieira VJ, D’Acampora A, Neves FS, Mendes PR, Vasconcellos ZA, Neves RD, et al. Capsular Contracture In Silicone Breast Implants: Insights From Rat Models. An Acad Bras Cienc. 2016 Sep;88(3):1459-70.

28 Rohrich RJ, Parker TH 3rd. Aesthetic management of the breast after explantation: evaluation and mastopexy options. Plast Reconstr Surg. 2007 Jul;120(1):312-5.

29 Nano MT, Gill PG, Kollias J, Bochner MA, Malycha P, Winefield HR. Psychological impact and cosmetic outcome of surgical breast cancer strategies. ANZ J Surg. 2005 Nov; 75(11):940-7.

$30 \mathrm{Ng}$ SK, Hare RM, Kuang RJ, Smith KM, Brown BJ, Hunter-Smith DJ. Breast Reconstruction Post Mastectomy: Patient Satisfaction and Decision Making. Ann Plast Surg. 2016 Jun;76(6):640-4.

31 Oiz B. Reconstrucción mamaria y beneficio psicológico. An Sist Sanit Navar. 2005; 28(Suppl 2):19-26.

32 Wilkins EG, Cederna PS, Lowery JC, Davis JA, Kim HM, Roth RS, et al. Prospective analysis of psychosocial outcomes in breast reconstruction: one-year postoperative results from the Michigan Breast Reconstruction Outcome Study. Plast Reconstr Surg. 2000 Oct; 106(5):1014-25.

33 Sawant KV, Xu R, Cox R, Hawkins H, Sbrana E, Kolli D, et al. Chemokine CXCL1-mediated neutrophil trafficking in the lung: role of CXCR2 activation. J Innate Immun. 2015; 7(6):647-58. 